\title{
К ПЕТРОГРАФИИ ГИПЕРГЕННЫХ СОЛЕЙ ВЕРХНЕКАМСКОГО МЕСТОРОЖДЕНИЯ
}

\author{
О.В. Коротченкова \\ Горный институт УрО РАН, г. Пермь
}

\begin{abstract}
Аннотация: На Белопашнинском участке Верхнекамского месторождения солей в одной из скважин была выявлена зона выщелачивания, приуроченная к границе соляной и соляно-мергельной толщ. Здесь отсутствуют покровная каменная соль и верхняя часть калийного разреза, а карналлитовые породы пласта Е полностью замещены вторичными сильвинитом и каменной солью. Изучение шлифов из образцов этой зоны с помощью оптического поляризационного микроскопа позволило выявить петрографические особенности этих пород.
\end{abstract}

Ключевые слова: Верхнекамское месторождение солей, гипергенные соли, сильвинитовая шляпа, апокарналлитовые соли, апокарналлитовое красящее вещество, выщелачивание солей.

\section{Введение}

Гипергенные каменная соль и сильвинит, локализованные на границе соляной и соляно-мергельной (СМТ) толщ, на Верхнекамском месторождении солей (ВКМС) известны давно. «Нормальный» разрез соляной толщи месторождения представлен (снизу вверх): подстилающей каменной солью, сильвинитовой зоной, карналлититовой зоной и покровной каменной солью. В самых первых солеразведочных скважинах, пройденных в 1925-1927 гг., были вскрыты сильвиниты, залегающие выше карналлитовых пород. И тогда же П.И. Преображенским был сделан вывод об их вторичности в результате замещения карналлитовой части разреза [4].

По данным предшественников [1, 3 и др.] сильвинитовые шляпы на месторождении приурочены к сводовым частям соляных антиклинальных структур, а их образование связано с выщелачиванием части калийного разреза в результате поступления вод из надсоляной толщи. На таких участках породы вышележащей соляно-мергельной толщи значительно преобразованы с формированием глинисто-гипсовой шляпы, породы покровной каменной соли частично или полностью отсутствуют, а карналлититы выщелачиваются и образуются вторичные сильвиниты. Первое, что отметили исследователи, это различие в окраске верхних и нижних сильвинитов - ржаво-бурая (гематитгетитовая) против сургучно-красной (существенно гематитовой). Этот факт позволил при изучении красящего вещества верхнего сильвина выявить его схожесть с карналлитовым [5].

\section{Исходные данные}

В 2019 г. при разведочных работах ООО «ЕвроХим - Усольский калийный комбинат» на Белопашнинском участке ВКМС (западный борт) одной из скважин были вскрыты глинисто-гипсовая (ГГШ) и сильвинитовая шляпы. Нижняя часть СМТ представлена глиной известковой темно-серой плотной с реликтовой микро-, тонкослоистой и брекчиевой текстурами, прослоями мощностью около $40 \mathrm{~cm} \mathrm{c}$ многочисленными гнездами гипса белого мучнистого (рис. 1). В качестве обломочного материала присутствует щебень первичного мергеля выветрелого до рыхлого состояния. Вблизи подошвы залегает новообразованная мергельгипсовая порода серая тонко-, микрослоистая мощностью около 6 м - тонкое переслаивание мергеля темно-серого и светло-серой гипсовой крупнокристаллической породы, с редкими секущими прожилками гипса белого и галита бесцветного. Верхняя часть калийного разреза (выше пласта Е) отсутствует, также как и покровная каменная соль. Для всей карналлитовой зоны характерно складчатое 


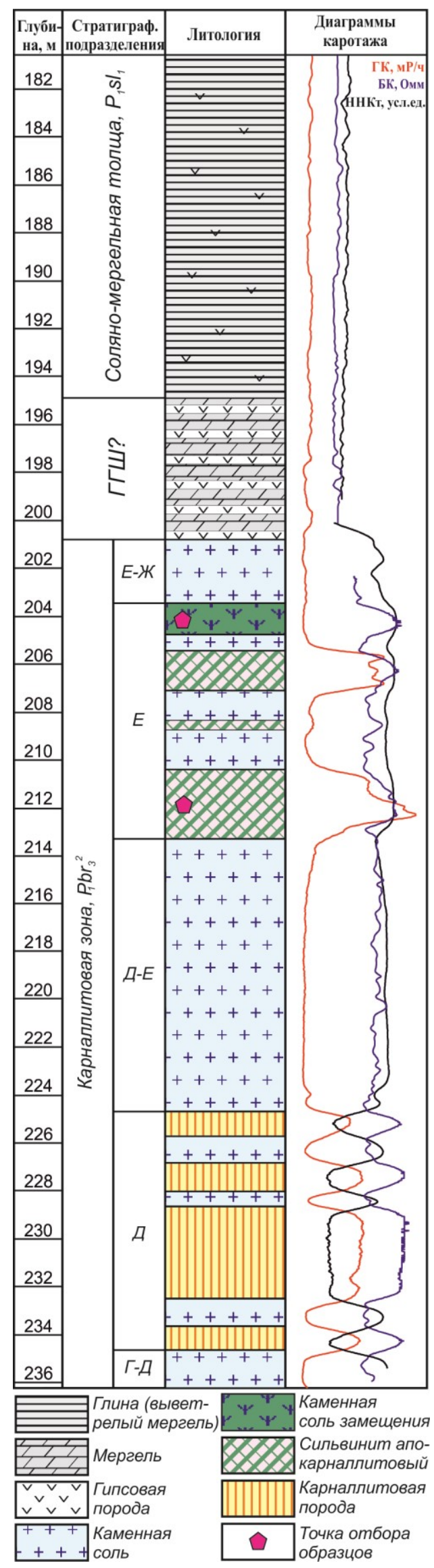

Рис. 1. Фрагмент геологической колонки скважины залегание под углом 30-50 (в единичных случаях $0-10^{\circ}$ ), часто наблюдаются замки опрокинутых складок. Пласт Е смят в крупную складку и в разрезе скважины прослеживается вертикальный контакт его с нижележащим пластом Д-Е. Ниже следует нормальный разрез карналлитовой зоны.

Апокарналлитовая часть пласта Е представлена (снизу вверх) вторичным сильвинитом (мощность 1,65 м) и вторичной каменной солью (1,3 м) (рис. 2). Для обеих пород характерна коричневая окраска, что затрудняет их диагностику в керне, однако они четко различаются на каротажных кривых (ГК и БК). Интересен тот факт, что между прослоями вторичных солей наблюдаются прослои «нормальной» каменной соли желтовато-серой мелкозернистой ритмично-тонкослоистой, которая характерна и для неизмененной части карналлитовой зоны. Такая же порода слагает вышележащий пласт, условно отнесенный к Е-Ж.

Для выявления петрографических особенностей гипергенных каменной соли и сильвинита было проведено исследование с помощью стереоскопа и поляризационного микроскопа проходящего (параллельные (||) и скрещенные (X) николи) и отраженного света Axioskop 40 Pol («Carl Zeiss», Германия) («ГИ УрО РАН», Г. Пермь).

\section{Результаты исследования}

Макроскопически сильвинит апокарналлитовый имеет желто-коричневый, красновато-коричневый цвет, крупнозернистую, часто идиоморфнозернистую структуру с элементами ориентированной и среднеслоистую текстуру. Отмечаются прослои каменной соли серой, желтовато-серой мелкозернистой средне-тонкослоистой частично будинированные (рис. 3a).

Микроскопически порода сложена крупнозернистым агрегатом сильвина, который образует ксеноморфные зерна с извилистыми очертаниями с весьма неравномерно рассеянными частицами и сгустками апокарналлитового красящего вещества. Галит присутствует в виде идиоморфных кристаллов размером 0,3-1,5 мм. В интерстициях отмечаются единичными иголочки ангидрита и гипса размером до 0,04 мм.

Цвет сильвинита обусловлен остаточным желтокоричневым оксидножелезистым веществом (рис. 3б), рассеянным преимущественно в сильвине в виде 


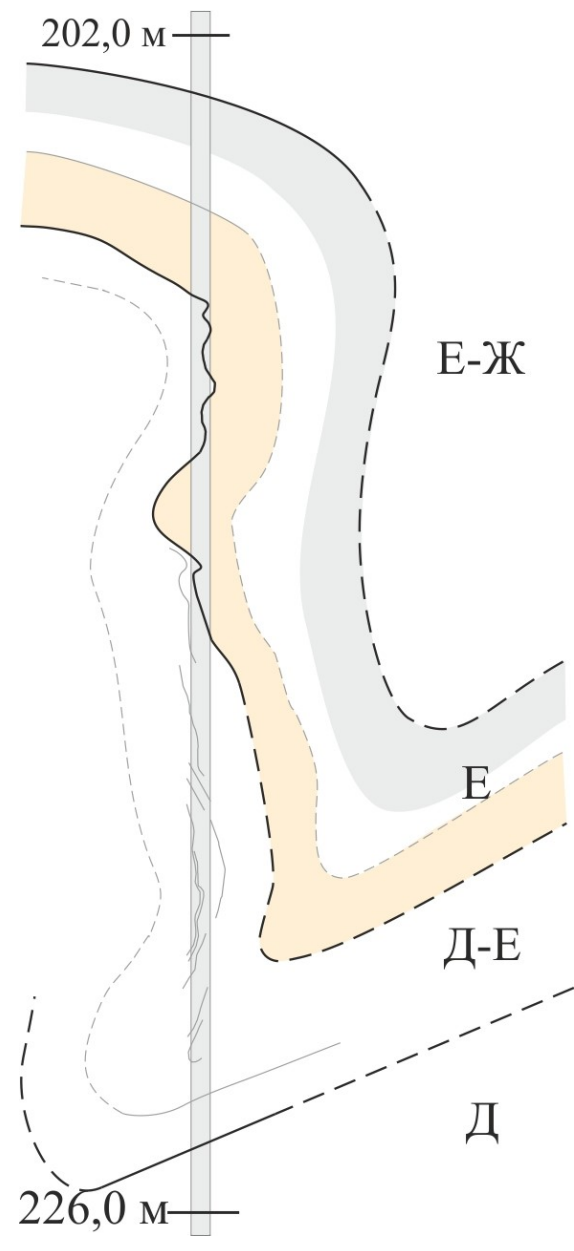

Рис. 2. Схематический разрез верхней части карналлитовой зоны в скважине:

серое - вторичная каменная соль, оранжевое - вторичный сильвинит, белое - нормальная каменная соль отдельных частиц (рис. 3в) или вдоль границ зерен в виде сгустков (рис. Зг). Оно состоит из желтых иголочек гетита, часто изогнутых, смятых и краснооранжевых пластиночек гематита, размер которых нередко достигает 0,02 мм (рис. 3б).

Каменная соль апокарналлитовая серая, светлосерая крупнозернистая неясносреднеслоистая. Прослоями мощностью 3-7 см порода имеет коричневый цвет, аналогичный таковому в сильвините апокарналлитовом, и крупнозернистую ориентированную структуру (рис. 3д).

Под микроскопом наблюдаются бесцветные угловатые изометричные или овальные зерна галита с извилистыми очертаниями размером 1-5 мм (рис. 3е), в единичных индивидах отмечаются фрагменты «перистого» внутреннего строения. Красящий материал, характерный преимущественно для коричневых прослоев и состоящий из микроиголочек гетита, часто деформированных, смятых, и микропластинок гематита, наблюдается в интерстициях зерен галита в виде сгустков неправильной формы или отдельных частиц. Нередко наблюдаются зерна с включениями оранжевого апокарналлитового красящего вещества, локализованными аналогично таковым в карналлите (вдоль дугообразных линейных дислокаций) (рис. 3ж). Часто в зернах фиксируются кубические или параллелепипедные, изредка неправильной формы, газово-жидкие включения размером от 0,002 мм до 0,08 мм, как вдоль линейных структур внутри зерна (рис. 33), так и в интерстициях. Галопелитовый материал, присутствующий в виде сильно фрагментированного до отдельных частиц прослоя, состоит из бурого глинистого материала с рассеянными частицами углефицированного растительного детрита, пинакоидальных кристаллов доломита размером 0,08-0,2 мм (отдельных и в сростках) и сгустков красящего вещества.

\section{Заключение}

Изучение апокарналлитовых каменной соли и сильвинита юго-западного части ВКМС позволило выявить следующие характерные петрографические особенности, в том числе выявленные предшественниками, которые отличают их от аналогичных первично-седиментационных солей:

- отсутствие отчетливых слоистых текстур;

- преимущественно пинакоидальная форма кристаллов доломита из галопелитового материала, которая характерна для доломита из карналлитовой зоны [2];

- красящее вещество представлено желтыми иголочками гетита и краснооранжевыми пластинками гематита. Такие частицы характерны для карналлита, где они рассеяны в объеме зерна, тогда как в гипергенных породах они локализуются чаще всего вдоль границ новообразованных галита и сильвина, формируя своего рода «рубашки» вокруг них; 

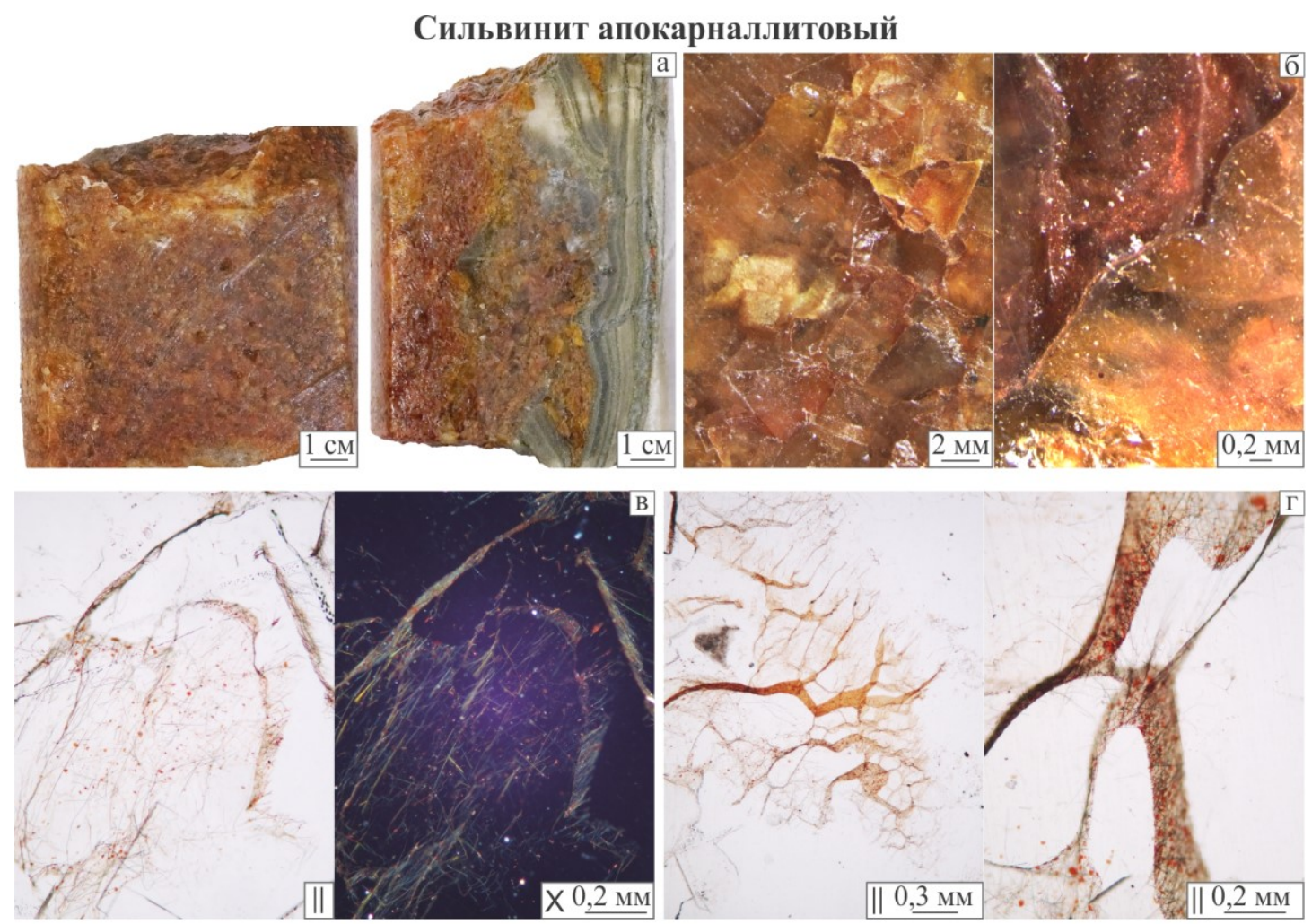

Каменная соль апокарналлитовая
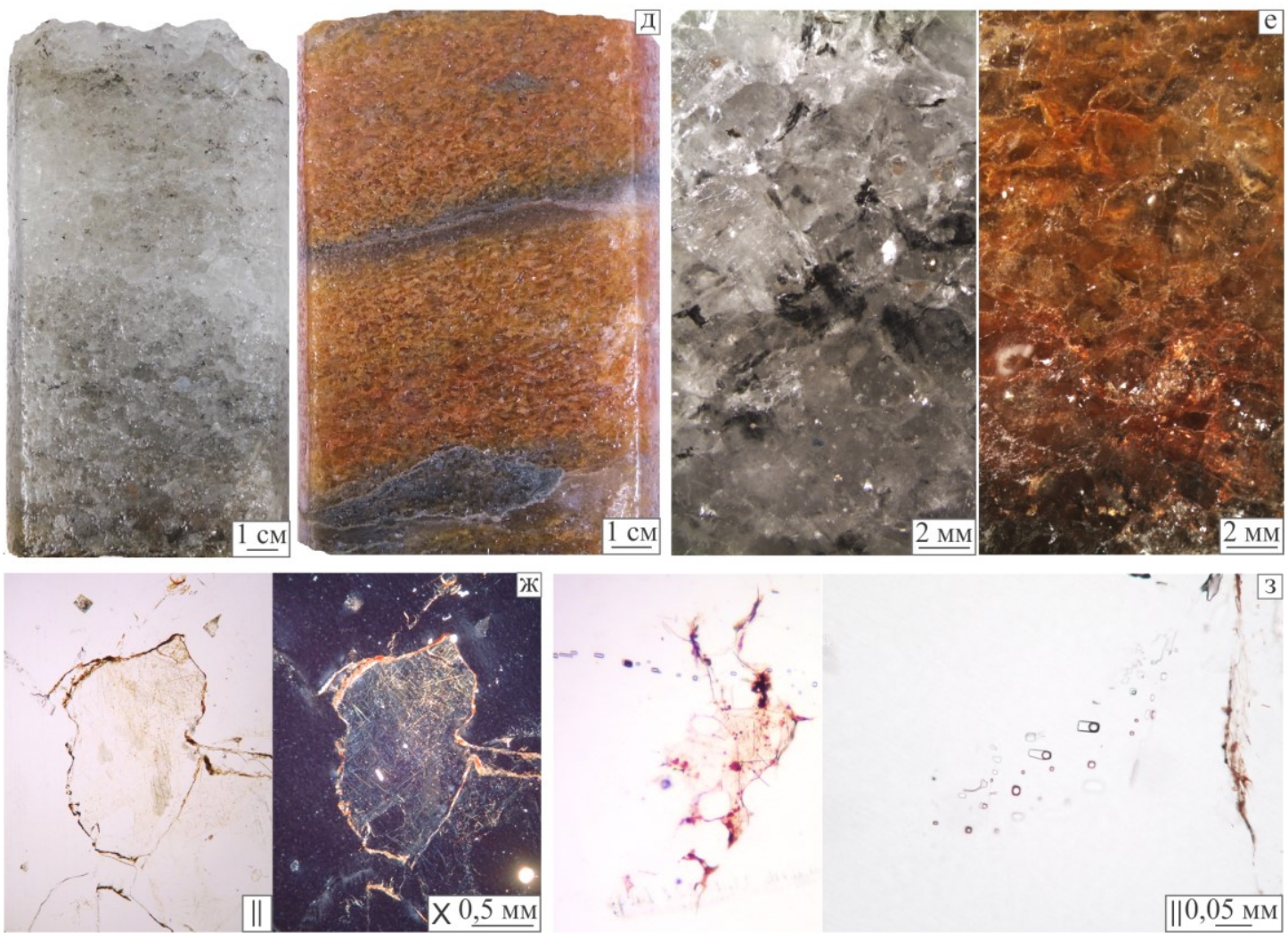

$-4) 3$

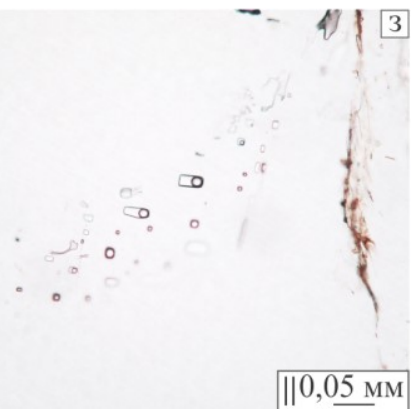

Рис. 3. Детали строения гипергенных солей: а - желто-коричневый цвет и крупнозернистая структура сильвинита; б - желтые иголочки гетита и оранжевые пластинки гематита вдоль границ зерен; в - апокарналлитовое красящее вещество, рассеянное в зерне сильвина; г - то же вдоль границ зерен; д - серая и коричневая каменная соль; е - крупнозернистая структура пород и красящее вещество,

локализованное вдоль границ зерен в коричневой разности каменной соли; ж - апокарналлитовое красящее вещество в зерне галита; 3 - сгустки красящего вещества и газово-жидкие включения в галите 
- косвенным признаком вторичности рассматриваемых пород может служить практически полное отсутствие ангидрита в их составе, тогда как в первичных каменной соли и сильвинитах он присутствует в достаточном количестве в составе галопелитового материала;

- наличие в изучаемой зоне выщелачивания прослоев «нормальной» каменной соли, для которой характерны в целом весьма отчетливая слоистая текстура, обычное слоистое строение годового слоя и темно-серые галопелитовые прослойки, указывает на насыщенный по $\mathrm{NaCl}$ состав рассолов.

\title{
Работа выполнена в рамках Программы ФНИ № НИОКТР AAAA-A-18-118040690031-5
}

\section{БИБЛИОГРАФИЧЕСКИЙ СПИСОК}

1. Иванов А.А., Воронова М.Л. О сильвинитовой шляпе Верхнекамского месторождения // Геология месторождений калийных солей: сб. ст. - Л., 1963. - С. 181-190. - (Тр. ВСЕГЕИ, новая сер., т. 99)

2. Коротченкова О.В. Особенности химизма карбонатных минералов Верхнекамского месторождения калийных солей (Пермский край) // Уральская минералогическая школа. - 2018. - № 24. - С. 93-97.

3. Кудряшов А.И. Верхнекамское месторождение солей / ГИ УрО РАН; [отв. ред. В.И. Раевский]. Пермь: [Соликам. тип.], 2001. - 429 с.: ил.

4. Преображенский П.И. Предварительный отчет по работе Соликамской разведочной партии за период с 1 октября 1925 г. по октябрь 1926 г. - Л.: Геологич. Комитет, 1927. - 94 с. - (Материалы по общей и прикладной геологии. Материалы по олбследованию Прикамского соленосного района. Вып. 104. Вып. 1).

5. Разумовская Е.Э. Причины и характер красной окраски калиевых соединений Соликамского месторождения // Иванов А.А. Отчет по разведочным работам ручным бурением, производившимся Соликамской партией Геологического комитета. - Л., 1927. - С. 34-41. - (Материалы по общей и прикладной геологии, вып. 105).

\section{О РОЛИ ВЕЧНОЙ МЕРЗЛОТЫ В ФОРМИРОВАНИИ КАРСТОВЫХ СИСТЕМ}

\author{
Н.В. Лаврова \\ Горный институт УрО РАН, г. Пермь
}

\begin{abstract}
Аннотация. Представлена роль вечной мерзлоты в развитии карстовых процессов при многократных оледенениях. Преобразование карстового субстрата рассмотрено на примере каналов и пустот, образующихся на границе современных ледников и коренных пород в горных системах Европы и Канады. Сложное строение толщи многолетнемерзлых пород при оледенении, особенно в зонах таликов, а также при деградации и наступлении ледников определяет особенности циркуляции подземных вод. Наряду с заполнением трещин и ранее образовавшихся пустот талые воды расширяют их и преобразуют. В результате образуются своеобразные формы, реликты которых можно наблюдать в современных карстовых системах. На примере органных труб в Кунгурской Ледяной пещере (Предуралье), а также находок криогенных минералов, предлагается модель преобразования карстующихся пород в условиях вечной мерзлоты.
\end{abstract}

Ключевые слова: вечная мерзлота, карстовые системы, Кунгурская Ледяная пещера, карстовый субстрат, циркуляция подземных вод, органные трубы, криогенные минералы.

\section{Введение}

Первичные пустоты на начальном этапе формирования небольших пещер и сложных карстовых систем образуются в результате эндогенных и экзогенных 